\title{
Pigmented juxtapapillary lesion as a form of presentation of parapapillary choroidal cavitation
}

\section{Cavitación peripapilar coroidea en el diagnóstico diferencial de lesión pigmentada yuxtapapilar}

\author{
Fernando López-Herrero*, José L. Sánchez-Vicente and Jorge L. Monge-Esquivel
}

Servicio de Oftalmología, Hospital Universitario Virgen del Rocío, Sevilla, Spain

\begin{abstract}
Juxtapapillary pigmented lesions represent an important diagnostic challenge in ophthalmology. We present a case of a juxtapapillary pigmented lesion whose multimodal imaging study evidenced a form of presentation of a peripapillary choroidal cavitation.
\end{abstract}

Key words: Peripapillary choroid cavitation. En-face OCT. Swept Source OCT. Degenerative myopia.

\section{Resumen}

Las lesiones pigmentadas yuxtapapilares representan un importante reto diagnóstico en oftalmología. Presentamos un caso de lesión pigmentada yuxtapapilar cuyo estudio de imagen multimodal evidenció tratarse de una forma de presentación de una cavitación coroidea peripapilar.

Palabras clave: Cavitación peripapilar coroidea. OCT En-face. OCT Swept Source. Miopía magna.

Available online: 08-05-2019 Rev Mex Oftalmol(Eng).2019;93(3):133-134

www.rmo.com.mx 2604-1731/@ 2019 Sociedad Mexicana de Oftalmología. Published by Permanyer México SA de CV. This is an Open Access article under the CC BY-NC-ND license (http://creativecommons.org/licenses/by-nc-nd/4.0/). 

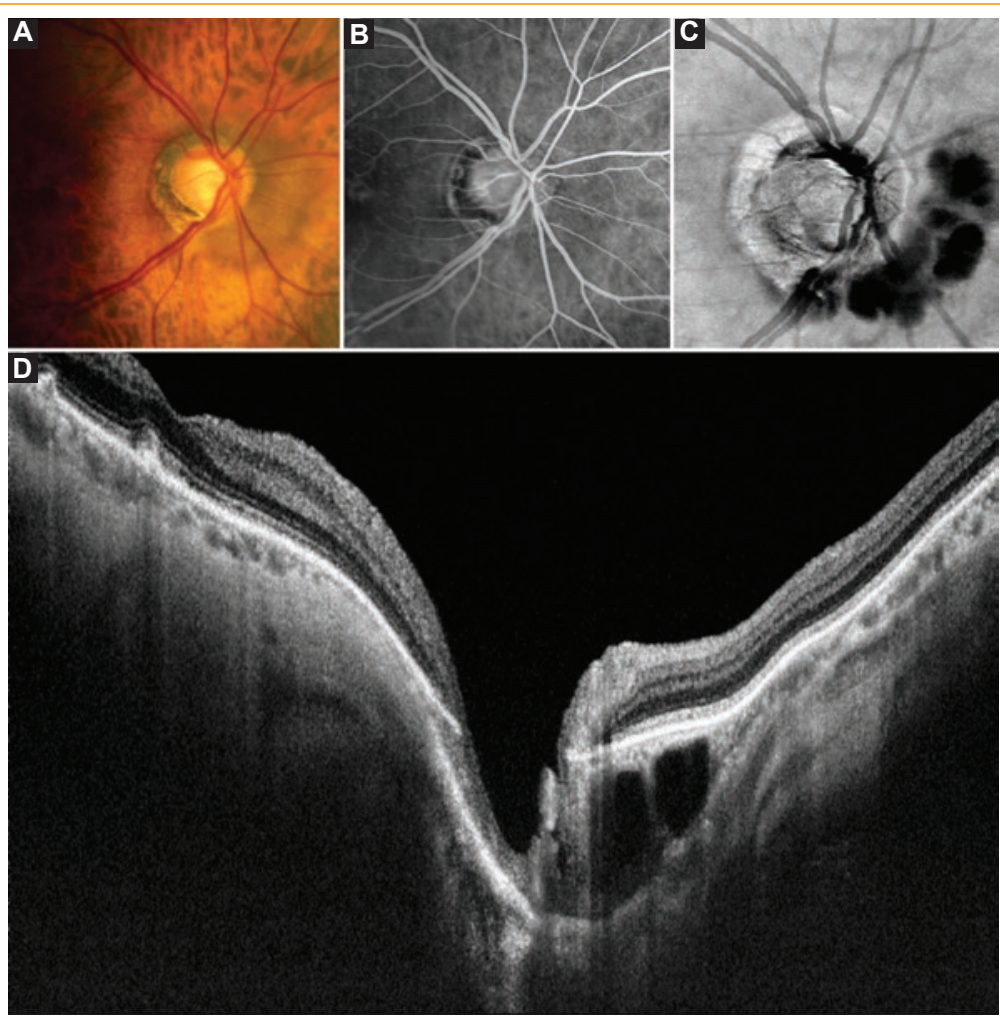

Figure 1. Multimodal analysis of the juxtapapillary pigmented lesion. A: Retinography image; B: Early phase fluorescein angiography; C: En-face optical coherence tomography (OCT) with choroid segmentation; D: Sweptsource OCT (DRI OCT Triton plus, Topcon Medical Systems, Inc., Europe) showing the characteristic findings of peripapillary intrachoroidal cavitations (PICCs).

A 64-year old patient with -7.0 diopters of myopia. A retinography of the right eye (OD) showed a well-demarcated, juxtapapillary nasal pigmented lesion (Fig. 1 A). In the early phases of the fluorescein angiography a faint screen effect was observed (Fig. 1 B). En-face optical coherence tomography (OCT) with choroid segmentation (Fig. 1C), highlighted the presence of hyporreflective spaces, apparently compartmentalized by interposed septa. Swept-Source OCT (Fig. 1 D) revealed the characteristic image of peripapillary intrachoroidal cavitations (PICCs), in this case with a type 3 staphyloma according to Curtin'1.

In conclusion, in contrast with the characteristic yellow-orange appearance, PICCs should also be considered in the differential diagnosis of peripapillary pigmented lesions ${ }^{2}$.

\section{Ethical disclosures}

Protection of human and animal subjects. The authors declare that no experiments were performed on humans or animals for this study.
Confidentiality of data. The authors declare that they have followed the protocols of their work center on the publication of patient data.

Right to privacy and informed consent. The authors declare that no patient data appear in this article.

\section{Conflicts of interest}

The authors declare no conflicts of interest.

\section{References}

1. Shinohara K, Moriyama M, Shimada N, Yoshida T, Ohno-Matsui K. Characteristics of Peripapillary Staphylomas Associated With High Myopia Determined by Swept-Source Optical Coherence Tomography. Am J Ophthalmol. 2016;169:138-44. doi: 10.1016/j.ajo.2016.06.033. Epub 2016 Jun 27.

2. Yeh SI, Chang WC, Wu CH, Lan YW, Hsieh JW, Tsai S, Chen LJ. Characteristics of peripapillary choroidal cavitation detected by optical coherence tomography. Ophthalmology. 2013;120(3):544-52. 